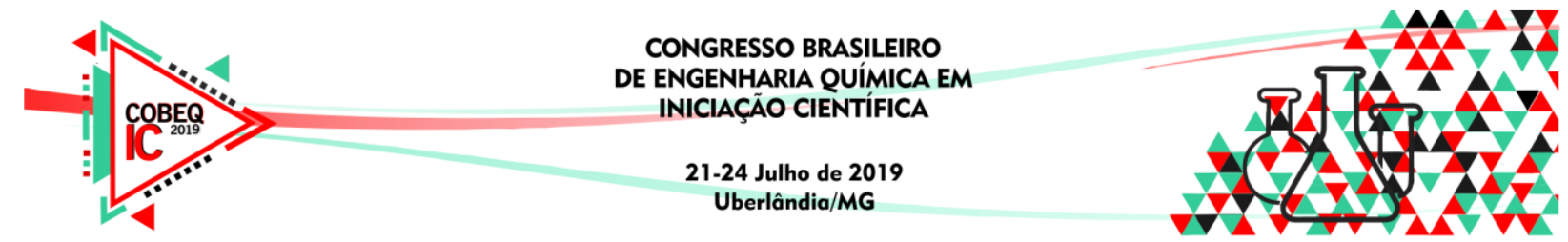

\title{
PERSPECTIVAS DA UTILIZAÇÃO DE ARRUDA (Ruta graveolens) NO ARMAZENAMENTO DE GRÃOS
}

\author{
A. O. ALMEIDA ${ }^{1}$, J. V. W. SILVEIRA ${ }^{1}$ \\ ${ }^{1}$ Universidade Federal dos Vales Jequitinhonha e Mucuri, Instituto de Ciência e Tecnologia \\ E-mail para contato: andressadeoliveira_1994@yahoo.com.br
}

\begin{abstract}
RESUMO-Existe um crescente interesse na substituição de produtos tóxicos e sintéticos, que causam enormes danos ao meio ambiente e à saúde humana-por produtos naturais. Essas aplicações estendem-se desde ao plantio, conservação e armazenamento, sobretudo no caso dos grãos. Uma das plantas que demostrou resultados interessantes foi à arruda, por possuir importantes propriedades larvicida, inseticida e antifúngica. Foram identificados mais de 45 compostos, sendo os mais eficientes às cetonas para o combate de pragas. Estas substâncias podem ser encontradas no extrato aquoso, pó das folhas, extrato orgânico e no óleo essencial. Dentre as classes de insetos e larvas que demostraram melhores resultados experimentais e teóricos foram as díptera, coleóptera e tylenchia e entre os fungos as leveduras. Os resultados demostraram que existem poucos estudos na área, restringindo a trabalhos utilizando a arruda como comparativo. Concluem-se assim boas perspectivas para pesquisas através da separação desses constituintes, ou da produção de estruturas de liberação controlada dos compostos, a fim de aplicar tanto no plantio, quanto industrialmente, em silos de armazenamento ou no produto final através do uso de embalagens ativas.
\end{abstract}

\section{INTRODUÇÃO}

Com os recorrentes danos ambientais que os produtos tóxicos causam ao meio ambiente e, sobretudo pelo aumento da expectativa de vida da população mundial, surgem novos estudos para a substituição desses produtos nocivos. Uma das formas mais eficientes é através da identificação dos ativos químicos das plantas. O setor que mais emprega produtos tóxicos e sintética é a agroindústria na forma de agrotóxico como antifúngicos, inseticidas e larvicidas, desde o tratamento do solo até o armazenamento final, principalmente no caso dos grãos.

Muitas plantas demonstram que possuem ativos com essas propriedades de combate a insetos larvas e fungos sendo elas as: arruda (Ruta graveolens), eucalipto-cheiroso (Eucalyptus citriodora), manjericão (Ocimum minimum), poejo (Mentha pulegium), tomilho (Thymus vulgaris), sálvia (Salvia officinalis), alho (Allium sativum L), atanásia (Tanacetum vulgare $L$ ). Dentre estas a que apresentou resultados mais satisfatórios foi à arruda, em especial no tratamento de grãos como o milho e o feijão na fase de armazenamento póscolheita.

A Ruta graveolens é o nome cientifico da popularmente conhecida arruda ou arrudafedorenta. É uma planta da família das rutaceace, originaria da região do Mediterrâneo e se desenvolveu bem em climas tropicais, subtropicais e temperados. É amplamente difundida e 


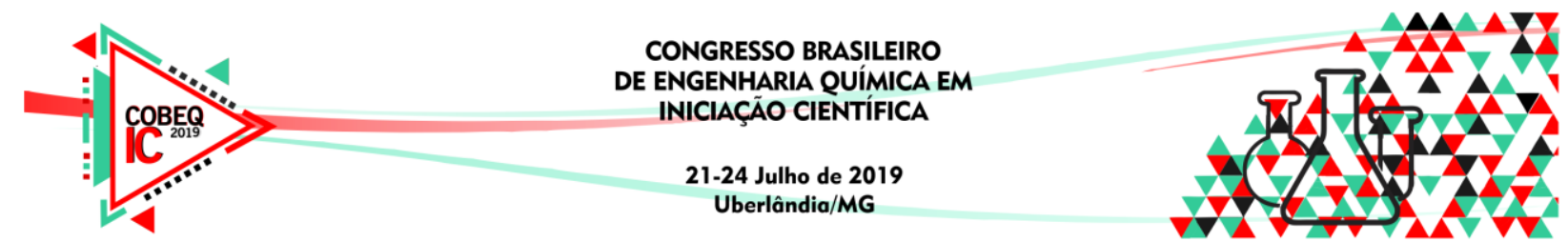

conhecida pelo planeta, sobretudo na Europa, África, América Tropical, Ásia (Japão, China e Índia) e Austrália.

Em relação aos constituintes pode-se haver variação em condições ambientais e de fatores genéticos submetidos à planta durante o plantio. Foram identificados os mais de 45 compostos analisados por PERERA et al.(2017) através de cromatografia de fibras de PDMS 30 e PA 85 M .Dentre os principais estão:2-decano,2-tridecanona, 2-decanona, 2tridecanona, 3,4-dietenil-3-metilciclo-hexeno, 4-(3,4- metilenodioxifenil) -2-butanona, ácido ciclo propano carboxílico, éster de dodealico, 2-octanona e 2-dodecanona.

Os processos de extração dos constituintes da arruda podem ser realizados de várias formas. As mais usuais são feitas por meio do extrato aquoso, pó in natura, extrato orgânico e óleos essenciais. Dentre eles o que melhor preserva as suas propriedades é através do método de extração do óleo essencial, porque garante um maior grau de pureza e pode ser dissolvido facilmente em outros solventes.

O procedimento de extração do óleo essencial da arruda pode ser feiro por meio do equipamento de hidrodestilação. É um sistema composto um extrator com transferência de vapor que arrasta e condensa o material de interesse, conforme demostra a figura 1. Esse procedimento é muito usual em laboratórios de pesquisa e para extração de óleo essencial no qual a matéria prima utilizada são folhas e caules de plantas in natura.

\section{Figura 1 - Sistema de hidrodestilação laboratorial}

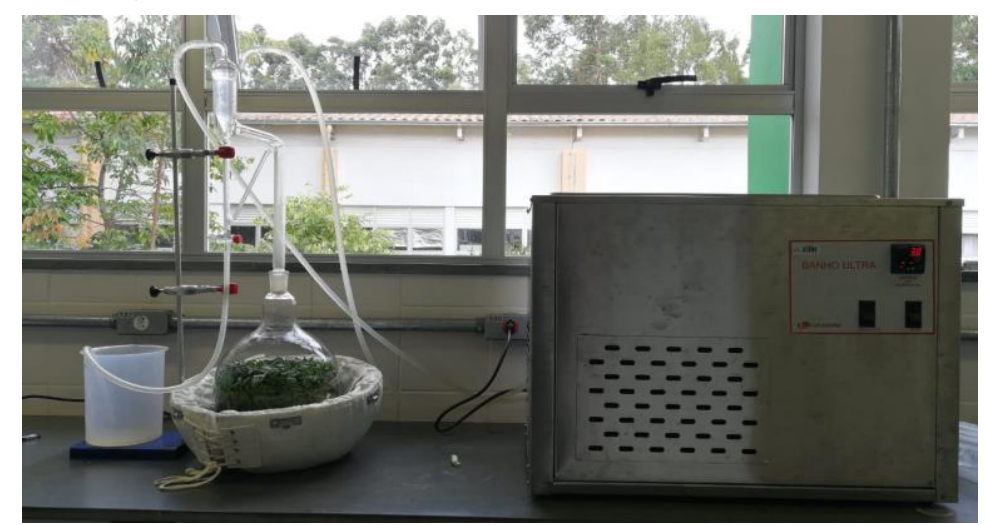

Fonte: Acervo do Autor

\section{METODOLOGIA}

O estudo constitui uma revisão bibliográfica de caráter analítico e sistemático, sobre utilização da Ruta graveolens voltada para a aplicação como larvicida., inseticida e antifúngica. Os dados foram coletados em plataformas de pesquisas acadêmicas e em diferentes idiomas. O critério de seleção foi baseado em publicações da última década e com enfoque nas áreas de ciências agrárias e química.

\section{POTENCIAIS DE UTILIZAÇÃO: BIOCIDA}

A escolha da planta para este estudo se deu por já ser muito empregado como fitoterápico na agricultura orgânica e também por ser uma planta de fácil adaptação em diferentes climas e, sobretudo no Brasil, sendo adequado ao clima de todas as regiões. Dentre 


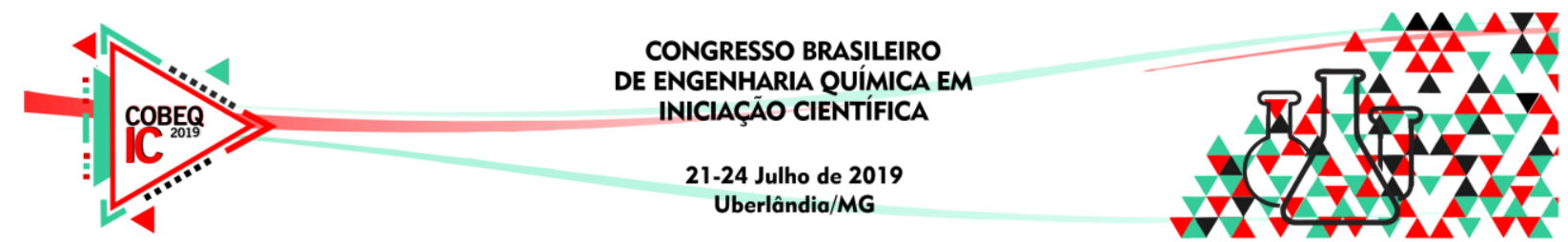

o potencial biocida dos componentes da planta, serão exploradas as funções inseticidas, larvicida e antifúngica. Além disso, a atividade bactericida também foi reportada pela planta em atividade antimicrobiana e citotóxica segundo IVANOVVA et al.(2005) e GIBKA et al.(2013).

\subsection{Inseticida}

Dos estudos realizados na área de prevenção e combate a insetos, os que apresentaram dados mais relevantes foram os que acometem o armazenamento de grãos, sobretudo no caso do milho e feijão, importantes cereais consumidos em larga escala no mundo.

A ordem dos insetos que demostra dados mais satisfatórios foram a: díptera GHABBARI et al (2018) e NIROUMANAND et al (2013) e coleóptera PERERA et al (2017), MAZZONETTO et al (2003) e DIAS et al (2016). Em comum possuem citoesqueleto quitinoso, o qual possibilita a interação entre os compostos presentes na planta com os insetos. Segundo Perera et al.(2017) foram identificadas as cetonas que dão caráter de repelência. Com base nas características e ordens dos insetos foi criada a tabela 1 contendo informações especificadas de quais insetos demonstraram suscetibilidade a planta.

Tabela 1 - Relação dos insetos e os métodos de combate usando arruda

\begin{tabular}{|c|c|c|c|}
\hline \multirow{2}{*}{ Ordem } & Nome Cientifico & Nome Popular & Tipo de Aplicação \\
\hline \multirow{3}{*}{ Díptera } & Diptera tephritidae & Mosquitos & Extrato orgânico \\
\cline { 2 - 4 } & Diptera Culicidae & Mosquitos & Extrato orgânico \\
\cline { 2 - 4 } & Aedes aegypti & Mosquito da Dengue & Óleo Essencial \\
\cline { 2 - 4 } & Anopheles albimanus Wiedemann & Mosquito preto & Extrato aquoso \\
\cline { 2 - 4 } & Culex quinquefasciatus & Muriçoca & Extrato aquoso \\
\cline { 2 - 4 } & Culex pipiens & Mosquito de casa & Extrato aquoso \\
\hline \multirow{2}{*}{ Coleóptera } & Acanthoscelides obtectus & Caruncho do feijão & Folhas desidratadas \\
\cline { 2 - 4 } & Sitophilus zeamais (Motschulsky) & Gorgulho de milho & Extrato orgânico \\
\hline
\end{tabular}

Pela tabela demostrou-se a variedade de insetos que contempla essa ordem, além disso evidencia as possibilidades de tratamento de insetos vetores de doenças como a dengue e a malária.

\subsection{Larvicida}

A Ruta graveolens mostrou uma planta com infinitas potencialidades e boas propriedades para o combate a diferentes tipos de insetos. Uma fase de desenvolvimento desses insetos é a fase ovo e larval, o qual ocorrem num período de 4 a 10 dias. Nesta fase as larvas acarretam diversos danos agrícolas como: redução ou perda total da produção, diminuição da qualidade do produto, infeção no solo e entre outras que dependem de fatores climática de cada localidade. Esses danos ocorrem sobretudo no setor da fruticultura, além disso na fase adulta esses insetos são vetores de transmissão de doenças. 


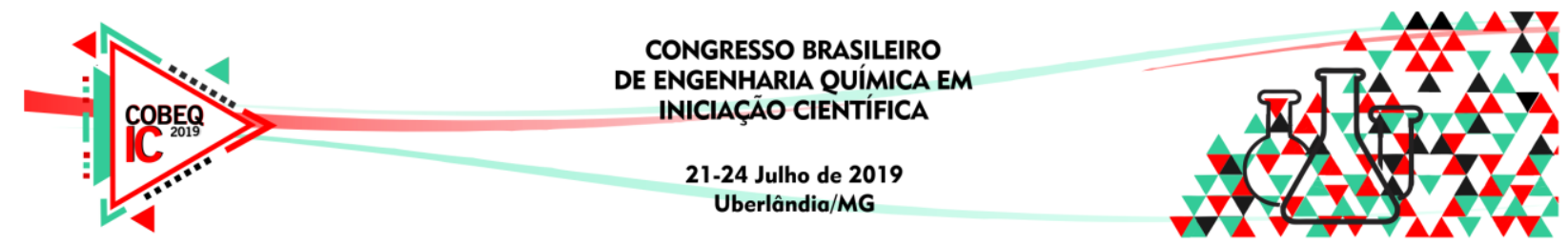

A ordem dos insetos que durante a fase larval causam prejuízos agrícolas são: díptera GHABBARIL et al (2017); CASTRO et al (2010) e ROHIEL (2013), coleóptera LANDOLF, et al (1999) e tylenchida por SASANELLI et al(2007) e FARIA et al, (2015). Estas ordens de larvas agridem diversas plantas que são economicamente importantes para a produção de alimentos, conforme a Tabela 2 que discrimina quais são eles.

Tabela 2 - Relação das larvas e os métodos de combate usando assuda

\begin{tabular}{|c|c|c|c|}
\hline Ordem & Nome Cientifico & Nome Popular & Tipo de Aplicação \\
\hline \multirow{5}{*}{ Díptera } & Ceratitis capitata & Moscas das frutas & Extrato orgânico \\
\hline & Rhagoletis mendax Curran & Moscas das frutas & Extrato orgânico \\
\hline & Rhagoletis cerasi $L$ & Moscas das frutas & Extrato orgânico \\
\hline & Syrphidae & Moscas de flores & Extrato orgânico \\
\hline & codling Cydia pomonella $L$ & Mariposa das frutas & Óleo essencial \\
\hline \multirow{3}{*}{ Coleóptera } & D. speciosa & Larva de flores e frutas & Extrato aquoso \\
\hline & Dione juno juno & Lagarta do maracujá & Extrato aquoso \\
\hline & Micorrízicos arbusculares & Larva nematoide & Extrato orgânico \\
\hline \multirow{3}{*}{ Tylenchida } & Meloidogyne incognita & Larva nematoide & Extrato orgânico \\
\hline & M. javanica & Larva nematoide & Extrato orgânico \\
\hline & Meloidogyne chitwoodi & $\begin{array}{l}\text { Larva de batata e } \\
\text { cenoura }\end{array}$ & Extrato orgânico \\
\hline
\end{tabular}

As larvas acometem frutos, folhas e grão em diferentes fases e em condições climáticas diversas. Sendo as mais desastrosas em frutos e no caso dos grão, sendo uma sequência de ataques de insetos que proliferam em grande silos de armazenamentos e até mesmo em embalagens final de acesso aos consumidores. Esse fato é recorrente em países emergentes e subdesenvolvidos que são carentes de tecnologias agrícolas , mesmo sendo suas economias se basearem predominantemente na agricultura, Segundo SHAYA (1997) aproximadamente $40 \%$ dos países ainda não encontraram tecnologias modernas de baixo custo, esse número se torna ainda mais significativos pois uma grade a quantidade de alimentos consumidos serem proveniente de grãos e sementes é gigantesca.

\subsection{Antifúngica}

Os fungos são organismos com características bem distintas. $\mathrm{O}$ grupo de fungos que a arruda apresentou propriedades fungicidas foi a de leveduras que crescem em colônias e são responsáveis por inúmeros danos na agricultura e no armazenamento de frutos e grãos.

A ordem dos fungos que apresentou susceptibilidade a Ruta graveolens foram Hypocreales, Helotialiales, Glomeralles, Diaporthales e Peronosporales OLIVA et al.(2003) e AGUIRRE et al (2016), contudo não são todos os fungos dessas ordens que possui a atividade biológica combatido pela Ruta graveolens, a qual possui a propriedade de reduzir e interromper o crescimento micelar. A Tabela 3 indica quais os fungos que podem ser 


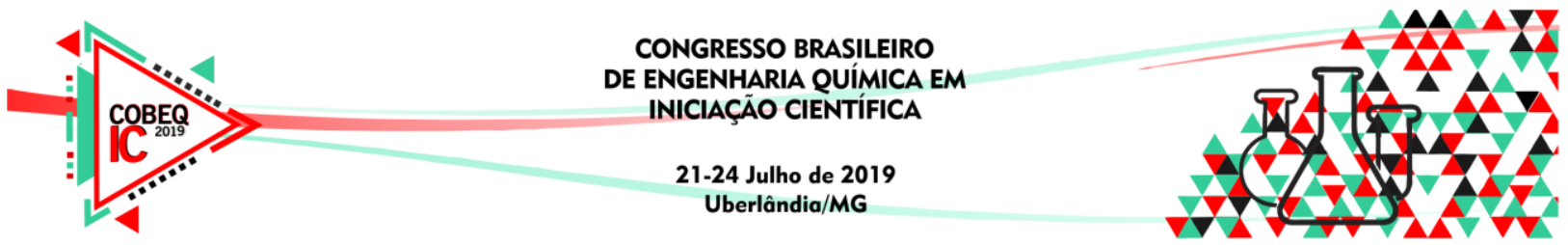

combatidos com a arruda, pois não se pode generalizar pelas ordens devido aos seus diferentes aspectos e adaptações nutricionais diferentes.

Tabela 3 -Relação dos fungos e os métodos de combate usando arruda

\begin{tabular}{|c|c|c|c|}
\hline \multirow{2}{*}{ Ordem } & NOME CIENTIFICO & NOME POPULAR & $\begin{array}{c}\text { TIPO DE } \\
\text { APLICAÇÃO }\end{array}$ \\
\hline \multirow{2}{*}{ Helotialiales } & Botrytis fabae & $\begin{array}{c}\text { Fungo da macha do } \\
\text { chocolate }\end{array}$ & Óleo essencial \\
\cline { 2 - 4 } & Botrytis cinérea & Podridão-cinzenta & Extrato orgânico \\
\hline Hypocreales & Fusarium oxysporim & - & Óleo essencial \\
\hline Glomeralles & Colletotrichum & - & Extrato orgânico \\
\hline Diaporthales & Phomopsis & - & Extrato orgânico \\
\hline Peronosporales & Prasmopara vitícola & Mofo & Extrato orgânico \\
\hline Eurotiales & Magnaphone oryzae & $\begin{array}{c}\text { Fungo do brusone } \\
\text { folicular do arroz }\end{array}$ & Óleo essencial \\
\hline
\end{tabular}

Uma das pesquisas que demostrou alguns fungos que afetam a plantas no geral, frutos e grãos foi realizado por Oliva et tal(2003). Foram isolados os compostos da arruda num extrato a base de hexano, em busca de dois metoxipsoralenos, quatro alcaloides de quinolona e uma quinoleína alcaloide, que são antifúngicos e presentes na Ruta graveolens. O estudo demostrou que a arruda pode ser efetiva no combate de fungos que proliferam no grão, porém os fungos devem ser estudados individualmente devidos às suas características serem bem distintas.

\section{CONSIDERAÇÕES FINAIS}

Por meio do estudo conclui-se que possuem poucos estudos na área, restringindo a trabalhos utilizando a arruda como comparativo com outras plantas, observou-se que os compostos constituídos por diversas cetonas presentes na planta são agentes de combate a insetos, larvas e fungos e podem ser usados para prevenção e combate de pragas de grão e sementes. Projeta-se que há boas perspectivas para pesquisas através da separação desses constituintes, ou da produção de estruturas de liberação controlada dos compostos, a fim de aplicar tanto industrialmente, em silos de armazenamento, como no produto final comercialmente vendido ao consumidor, através de embalagens ativas.

\section{REFERÊNCIAS}

CASTRO, E. C.;VARGAS, L.L;BAUSTISTA A. R. Efecto tóxico del extracto acuoso de Ruta graveolens L. (Rutaceae) sobre larvas de Anopheles albimanus Wiedemann, 1820 y Culex quinquefasciatus Say, 1823 (Diptera: Culicidae), en condiciones experimentales. Entomotropica Vol. 25(1): 11-18,2010. 


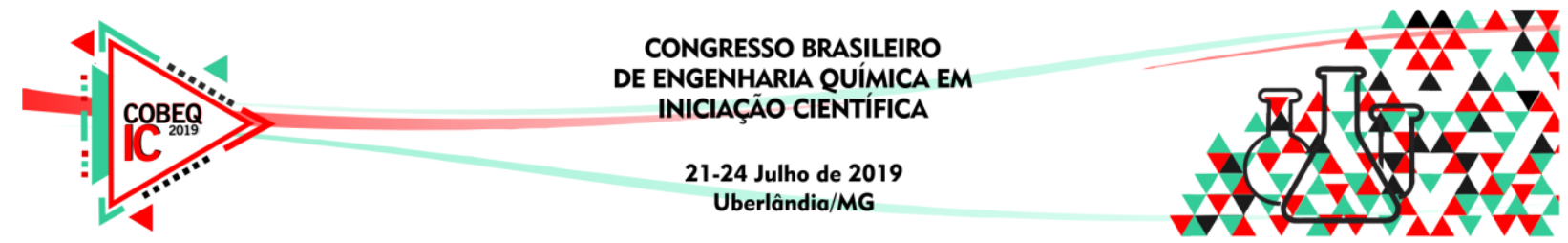

FARIA, J. M. S.; SENA, I.; RIBEIRO, B. First report on Meloidogyne chitwoodi. hatching inhibition activity of essential oils and essential oils fractions.Journal of pest Science, Volume 89, Edição 1, pp. 207-217,2015.

GHABBARI, M.; GUARINO, S.; CALECA, V. et al. Behavior-modifying and insecticidal effects of plant extracts on adults of Ceratitis capitata (Wiedemann) (Diptera Tephritidae). Springer-Verlag GmbH Germany, part of Springer Nature 2018.Jornal of Pest Science (2018) p.907-917,2018.

GIBKA, J. ; STYCZYÑSKA, A. K. ; GLIÑSKI, M. Antimicrobial Activity of Undecan-2-one, Undecan-2-ol and Their Derivatives. Journal Journal of Essential Oil Bearing Plants ,vol 12,p.695-615,2013.

IVANOVAA, A. MIKHOVAA, B.; NAJDENSKIB, H.; TSVETKOVAB, I.Antimicrobial and cytotoxic activity of Ruta graveolens. Fitoterapia 76(2005)344-347,2005.

MAZZONETTO, F. e VENDRAMIM, J... Effect of Powders from Vegetal Species on Acanthoscelides obtectus (Say) (Coleoptera: Bruchidae) in Stored Bean. Neotropical Entomology 32(1) p.145-149,2003.

OLIVEA, A.; MEEPAGALA, K. M. DAVID et al. Natural Fungicides from Ruta graveolens L. Leaves, Including a New Quinolone Alkaloid.Journal of agricultural and food chemistry. Vol. 51, No. 4, 2003 p.890-896, 2003.

PERERA, A.; KARUNARATNE, M.M.S e CHINTHAKA, S.D.M. Biological activity and secondary metabolite profile of Ruta graveolens leaves against maize weevil infestations . Journal of Entomology and Zoology Studies(2017)p.233-241,2017.

REIS, K. B. Extrato padronizado de Ruta graveolens 1.: Avaliação de seu potencial no controle do brusone em arroz.2013,146f. Dissertação de Mestrado em Ciências Farmacêuticas. Faculdade de Farmácia- Programa de pós-graduação em ciências farmacêuticas. Universidade Federal de Goiás,2013.

ROJHT, H.; KOŠIR, I. J. e TRDAN, S. Chemical analysis of three herbal extracts and observation of their activity against adults of Acanthoscelides obtectus and Leptinotarsa decemlineata using a video tracking system. Journal of Plant Diseases and Protection, 119; p. 59-67,2013.

SASANELLI, N. A; A., A; B D'A. Nematicidal properties of leaf extracts of Ruta graveolens inoculated with arbuscular mycorrhizal fungi . Russian Journal of Nematology, Volume 15, Issue 1, 2007, Pages 65-73,2007. 